\title{
Brief Discussion on Presentation of Brand Culture in Food Advertising Design
}

\author{
Xiangrui Huang, Chenjin Tang \\ School of Arts and Communications \\ Wuhan Polytechnic University \\ Wuhan, China
}

\author{
Jing $\mathrm{Hu}^{*}$ \\ School of Arts and Communications \\ Wuhan Polytechnic University \\ Wuhan, China
}

\begin{abstract}
Nowadays, the main groups of food consumption are the post-80s, post-90s and post-00s. Most of these young people grow up in the era of material prosperity. They pay special attention to the spiritual feelings brought by material consumption. Therefore, commercial food should not only strengthen its own tas te, health and nutrition, but also highlight its characteristics and cultural connotation, and fully embodies it with the advertising promotion. By further shaping the brand culture image in food advertising, enterprises will subtly convert a positive influence on consumers' dietary concept and lifestyle.
\end{abstract}

Keywords_-food; advertising design; brand culture

\section{INTRODUCTION}

For the presentation of brand culture in food advertising design, this paper mainly focuses on the following two aspects: first, the endowment and exploration of food culture connotation; second, the positioning and development of food culture.

\section{THE ENDOWMENT AND EXPLORATION OF FOOD CULTURE CONNOTATION}

As the saying goes, "Food is the first necessity of the people", the importance of food ranks at the top of human beings' four major necessities of the clothing, food, shelter and traveling. Correspondingly, in daily life, food-related advertisements are also extremely active and abundant. According to statistics from relevant agencies, food is the second most popular industry. Facing the various food advertisements, the public would often suffer aesthetic fatigue or difficulty in choosing. For the food itself, the publicity effect will inevitably be reduced. Therefore, how to explore the cultural connotation of food to highlight the performance of its advertising creativity is an important topic at present. [1]

The creative expression of advertisement is the visual manifestation of food brand culture. Meanwhile, the connotation of food culture needs to be displayed in advertisement by means of visual language symbols. In the process of shaping the image of food culture, we should not only consider the material attributes of food presented in advertisements, such as color, taste, shape and many other factors, but also pay full attention to the correct concept of food consumption, which means to promote a positive concept of consumption and lifestyle, and that is also the embodiment of its culture. In real life applications, some advertisements only emphasize the increase in sales, especially for some food with little nutritional value. However, they ignore the humanistic care in advertisements. Therefore, if we can reflect the dietary style and life concept of a nation or a region from the perspective of food, it will greatly promote the inherent cultural significance of food. The promotion of culture by food and the development of brand by culture would enhance each other. Throughout the excellent food advertising, we could find out some feature in common - visual creative performance as well as the expression of a certain cultural concept in a gentle and subtle way. The publicity effect is unexpected yet reasonable. Take the American beverage brand Coca-Cola as an example. It is a symbol of American culture, representing the Americans pursuit of freedom and equality, and their ardent national character. Among Coca-Cola's many advertisements, there is one appealing: a young man is buying a Coke from a vending machine. When he pays the money on the machine, the picture switches to the inside of the machine, showing an animated Coca-Cola production workshop. Numerous animal workers begin to work - pouring Coke into bottles, putting caps on, freezing them up, and finally the bottle sliding to the shipping port under the cluster of all the animal workers. The youth immediately opens it and drinks, and a strong feeling of fresh and refreshing arises naturally. From the introduction of the Coke bought by the youth, to the orderly production of animal workers, a picture is presented to consumers visually. In the picture transmission, it also implicitly molds the cultural image of Coca-Cola which is full of passion, vitality and unity, and cooperation. The bold content performances, as well as the blazing and bright colors, together complete the output of the cultural image of Coca-Cola. Meanwhile, the advertisement also vividly shows the processing of Coca-Cola to consumers, and conveys the characteristics of food freshness and safety, so that consumers can establish the impression of a trustworthy brand. In the late 70s of last century, accompanied by the rise of Pepsi Cola, Coca-Cola's position was being challenged, forcing it to change its marketing strategy. Coca-Cola tried to save the market by changing the taste of drinks. To this end, instead of emphasizing the elements of passion and warmth in the past, Coke-Cola boldly used the scene of young people frolicking, trying to create its new taste, and new feelings of culture. However, on the contrary to expectations, after being released to the advertising market, it encountered many public complaints and dissatisfaction. The reason is that Coca-Cola's elaborate taste has been deeply rooted in the hearts of the American people for many years, successfully solidified the American dietary habits, and rose to a traditional American 
spirit. Coca-Cola's abandonment of traditional formula means a betrayal in spiritual culture. During the time of rapid development in the US, the destiny of Coca-Cola brand culture has been closely bound up with its nation's.

Through the visual expression of food advertisements, we can identify the cultural tendency behind them. This requires the spread of food advertising not only to stay on the essential attributes, but also consider the food and its related factors, such as physical geography, regional culture, and ideology, so that the profound cultural heritage could be condensed in the food, and thus the food becomes a carrier to promote national culture. Food has its inherent cultural characteristics, and the people in each region have a sense of kindness and respect for their own national food. The integration of culture into food will strengthen consumers' psychology of the common destiny of food brands. Japanese food is particularly prominent in this aspect: in a Japanese orange juice advertisement, the whole picture shows the original ecological process from picking to fresh pressing, intuitively expresses the advocate of Japanese Zen - to respect nature, and to remove the flashy national gene, thus the national character is vividly reflected in the product advertisement.

\section{THE POSITIONING AND DEVELOPMENT OF FOOD CULTURE}

Material abundances directly lead to the richer varieties and forms of food, and correspondingly lead to increasingly fierce competition among the food industry. There is an urgent need to change the current monotonous trend in domestic food advertising design, and to break the self-bluffing mode. The lack of accurate positioning, or the distinction of food's individuality, often results in the failure of locating the specific consumer group, which lows the product sales, and weakens the competition ability of that enterprise.[2] For those foods with unique features, which also incorporate certain cultural characteristics into the advertisement, there must be a sense of novelty and depth in the advertisement. In the process of dissemination, even if it does not bring about an immediate surge in sales, it will provoke a lot of attention and memory.

\section{A. Identify the unique cultural orientation of products}

In the domestic drinking water market, most of the drinking water is taking "pure" as a selling point. To stand out in the drinking water market, through thinking about the relationship between water and human body, Nongfu Spring found that most of the pure water on the market is lack of trace elements necessary for human body. This major defect obviously violates the original intention of maintaining the normal physiological function of the human body and is inconsistent with human health needs. Therefore, Nongfu Spring relocated its own position, and then the concept of "a little bit sweet" is conveyed through its advertising pictures. Why is it a little bit sweet? It further arouses the audience's thinking, suggesting that being "sweet" is due to the trace elements contained in Nongfu Spring, producing a natural and healthy taste. As a result, "a little bit sweet" has become a unique cultural characteristic of Nongfu Spring, and the response to it is enthusiastic after the replacement to the advertising market.

\section{B. Expand brand culture space}

After the initial success of the Nongfu Spring's identification, it did not stop there. After that, through sponsoring various large-scale sports events, the enterprise further strengthened the cultural image of it in maintaining physical fitness. This is a great pioneering effort to combine the brand image of Nongfu Spring with the sports culture, to create a drinking brand suitable for both ordinary people and professional athletes. By doing so, Nongfu Spring effectively expanded the cultural space and market position of its brand.

Since Nongfu Spring natural water was selected as the "Exclusive Training and Competition Drinking Water for Sydney Olympic Games China Sports Delegation” in February 2000, it has become a microcosm of the brand's internationalization. From the viewpoint of Chinese sports delegation, they were obviously very cautious and strict in the choice of athletes' drinking water, which required the water being natural, healthy and safe (without doping). Nongfu Spring had been laying the groundwork for this by exploring its own drinking water culture, which was "a little bit sweet". In the following four years, the enterprise worked closely with the Chinese Olympic Committee. The fate of Nongfu Spring is tied up with the development of China's sports industry, walking together with weal and woe. The case of Nongfu Spring finding their cultural orientation fully shows that the development of food culture also needs to seek the support of specific cultural space. We believe that if the food branding can seize this point, then its promoting effect will get twice the result with half the effort.

\section{Conclusion}

Social needs are changing, and consumers are iterating, so food brand culture needs to be closely associated to the current social and cultural characteristics, to get the favor of the mainstream consumer groups. It is not difficult to see from the above examples that if food brands want to succeed in development, they must fully explore the inherent cultural characteristics of themselves in advertising design and publicity, so as to convey beneficial health values and lifestyles, thereby leading the correct view of consumption and life; secondly, they must rely on their own brand culture consistent with the brand. Cultural activities expand the space of brand growth and realize the organic combination of their complementary advantages. In a competitive business society, consumers have more choices. To be effectively identified by consumers in a vest of food brands, distinct and unique culture is essential, then the food can achieve the dual satisfaction in both the material function and the spiritual needs.[3]

\section{REFERENCES}

[1] Mao Jinghua. Creative Strategies for Food Advertising [J]. News Enthusiasts, 2008(6):57.

[2] Hu Kaifeng, Zhao Kehua, Shi Hua, Lin Pengzhang, Sun Qingzhong, Feng Huiming. Current Situation and Countermeasures of Food Advertising Management [J]. Public Health Management in China, 1995 (02).

[3] Yang Mi, Yu Ming. Analysis of Modern Food Advertising Techniques [J]. Arts Education Research, 2015 (03). 